14.2

\title{
Иммобилизация фотодитазина на пористых частицах ватерита и исследование стабильности системы в модельных средах
}

\author{
(C) Д.Б. Трушина, ${ }^{1,2,3}$ Т.Н. Бородина, ${ }^{3,2}$ В.В. Артемов, ${ }^{3}$ Т.В. Букреева ${ }^{1,3}$ \\ ${ }^{1}$ Национальный исследовательский центр „Курчатовский институт“, \\ 123098 Москва, Россия \\ ${ }^{2}$ Первый Московский государственный медицинский университет им. И.М. Сеченова, \\ 119991 Москва, Россия \\ ${ }^{3}$ Федеральный научно-исследовательский центр „Кристаллография и фотоника“ РАН, \\ 119333 Москва, Россия \\ e-mail: trushina.d@mail.ru
}

(Поступило в Редакцию 7 февраля 2018 г.)

Приведены результаты по иммобилизации российского фотосенсибилизатора второго поколения „Фотодитазина“ на пористых частицах ватерита (метастабильная модификация карбоната кальция) двух различных размеров. Эффективность адсорбции составляет 3.0 и $3.2 \mathrm{wt} \%$ фотодитазина для частиц ватерита со средним диаметром 5 и $0.5 \mu \mathrm{m}$ соответственно. Получены кривые десорбции фотодитазина из частиц ватерита в зависимости от состава дисперсионной среды (в воде и в растворе бычьего сывороточного альбумина). Установлено, что в воде частицы ватерита подвержены перекристаллизации по механизму растворение--осаждение. Присутствие молекул белка в физиологической концентрации позволяет стабилизировать метастабильные частицы ватерита микронного и субмикронного размера не менее чем на 17 суток.

DOI: 10.21883/JTF.2018.09.46426.52-18

\section{Введение}

Активно развивающимся биомедицинским направлением нанотехнологий является разработка носителей лекарственных веществ на основе нано- и микрочастиц. Особенно важным представляется разработка таких контейнеров для высокотоксичных противоопухолевых веществ, поскольку помимо снижения вводимой в организм дозы это может способствовать повышению градиента „опухоль-нормальная ткань“. В настоящее время одним из перспективных фотосенсибилизаторов, предназначенных для флуоресцентной диагностики и фотодинамической терапии злокачественных опухолей, является российский фотосенсибилизатор группы хлоринов Е6 второго поколения „Фотодитазин“ $[1,2]$. Несмотря на слабо выраженную системную токсичность, повышение локальной концентрации препарата в опухоли является актуальной задачей, которую предлагается решить с помощью введения лекарственного вещества в организм в составе биосовместимых частиц.

Наноструктурированные частицы карбоната кальция представляют интерес в качестве носителей биологически активных молекул благодаря своей биосовместимости, растворимости при слабокислом значении $\mathrm{pH}$, низкой токсичности и большой сорбционной емкости [3]. Простой метод получения частиц карбоната кальция [4] и отсутствие необходимости в сложном оборудовании и дорогостоящих химических реактивах делают такие частицы привлекательными с точки зрения производства лекарственных форм (препаратов) на их основе. В настоящее время карбонат кальция применяется в качестве пищевой добавки, а также в качестве наполнителя и пигмента для различных таблеток. Как основное активное (действующее) вещество $\mathrm{CaCO}_{3}$ используется в препаратах, оказывающих антацидное (снижающее кислотность желудка) действие [5]. Помимо этого существует ряд работ, в которых предлагается использовать сферические частицы карбоната кальция в качестве носителей лекарственных веществ [6-8]. Системы доставки активных веществ на основе частиц карбоната кальция в отличие от многих других систем на основе неорганических носителей могут выводиться из организма за счет растворения частиц в кислой среде, например биологических жидкостях, фагоцитах, лизосомах, раковых клетках [9]. Более того, утверждается, что ионы кальция после растворения частиц $\mathrm{CaCO}_{3}$ в организме могут участвовать в процессах формирования костной ткани, не вызывая нежелательной кальцификации [10]. Это позволяет рассматривать частицы $\mathrm{CaCO}_{3}$ в качестве потенциальных перспективных носителей биологически активных веществ.

В природе карбонат кальция существует в виде трех кристаллических модификаций, среди которых только одна - ватерит, образует частицы с пористой структурой и развитой поверхностью, что и определяет востребованность таких частиц в задачах, связанных с иммобилизацией и высвобождением активных веществ. Благодаря высокой пористости частиц, большой площади и заряду поверхности, частицы ватерита обладают хорошей адсорбционной способностью к широкому ряду соединений. Ранее было показано, что частицы ватерита способны адсорбировать энзимы $[11,12]$, а также раз- 
нообразные низкомолекулярные вещества, среди которых центральный анестетик лоперамид [13], анальгетик ацетаминофен [14], ряд красителей [14,15].

Особый практический интерес представляют частицы ватерита субмикронных размеров, пригодные для in vivo использования. Трудность получения таких частиц связана с тем, что ватерит является метастабильной модификацией карбоната кальция, и его частицы в присутствии воды трансформируются в термодинамически стабильные не пористые кристаллы кальцита. В связи с этим получение частиц ватерита и дальнейшая работа с ними требует специальных подходов.

Цель настоящей работы заключалась в получении частиц карбоната кальция двух различных размеров и иммобилизации фотосенсибилизатора фотодитазина. Помимо этого большой интерес представляет исследование стабильности частиц ватерита с инкапсулированным содержимым в зависимости от состава дисперсионной среды.

\section{Экспериментальная часть}

\section{Материалы}

Хлорид кальция, карбонат натрия, бычий сывороточный альбумин (БСА), глицерин производства SigmaAldrich (Германия). Для исследования загрузки пористых частиц был использован фотодитазин (ООО „ВетаГранд“) - российский фотосенсибилизатор второго поколения, предназначенный для фотодинамической диагностики и терапии злокачественных опухолей. Во всех экспериментах использовали деионизованную воду, полученную на установке водоочистки Millipore Milli-Q Plus (США, Канада).

\section{Получение частиц карбоната кальция}

Коллоидные частицы карбоната кальция получали как продукт массовой кристаллизации. Для получения частиц микронных размеров использовали известную методику [16]. Для получения субмикронных частиц ватерита методику модифицировали в соответствии с результатами предыдущих исследований $[17,18]$. Суспензию частиц центрифугировали 2-10 min при 5000-12000 rpm в зависимости от их размеров и троекратно промывали деионизованной водой. Далее все образцы высушивали в сушильном шкафу при $70^{\circ} \mathrm{C}$ и хранили в герметичной пробирке при комнатной температуре, либо сразу же использовали для дальнейших экспериментов.

\section{Иммобилизация фотодитазина}

Иммобилизацию фотодитазина проводили путем адсорбции вещества на предварительно синтезированных частицах ватерита в соответствии с методикой, описанной в [17].

\section{Высвобождение фотодитазина из частиц ватерита}

Навески частиц ватерита с инкорпорированным фотодитазином диспергировали в $2 \mathrm{ml}$ воды или раствора БСА $(30 \mathrm{mg} / \mathrm{ml})$. Образцы выдерживали при $25^{\circ} \mathrm{C}$ на шейкере (500-800 rpm) в течение определенных промежутков времени. Затем образцы центрифугировали и спектрофотометрически определяли концентрацию вещества в супернатанте.

\section{Методы}

\section{Сканирующая электронная микроскопия}

Размер и морфологию образцов карбоната кальция изучали с помощью сканирующей электронной микроскопии (СЭМ) на приборе JSM-7401F (JEOL, Япония). Для получения изображений в режиме вторичных электронов использовали низковольтный режим. Это связано с тем, что исследуемые образцы являются непроводящими объектами. Режим ускоряющего напряжения в $1 \mathrm{kV}$ позволил также более детально изучить поверхность капсул. Дополнительно к этому для компенсации накапливающегося на поверхности заряда применяли режим быстрого сканирования с последовательным интегрированием 64 кадров.

\section{Спектрофотометрия}

Эффективность загрузки частиц ватерита фотодитазином и интенсивность его высвобождения оценивали с помощью двулучевого сканирующего спектрофотометра Lambda-C650 (Perkin Elmer, США) с диапазоном длин волн 190-900 nm, измерения проводили в кварцевых кюветах. Фотодитазин имеет четыре характеристические полосы поглощения на длинах волн 405, 504, 608, $662 \mathrm{~nm}$, эффективность загрузки активного вещества в частицы ватерита определяли по наиболее интенсивному пику $(405 \mathrm{~nm})$. Для получения значения оптической плотности не более единицы исследуемые растворы разбавляли деионизованной водой. Количество фотодитазина, адсорбированного на частицы ватерита, определяли с помощью предварительно построенной калибровочной прямой по разнице концентрации раствора вещества после адсорбции по отношению к исходному раствору. Эффективность капсулирования определялась следующим образом: $E C=\frac{K_{d}-K_{\text {sup }}}{K_{\text {sup }}} \cdot 100 \%$, где $K_{d}-$ количество вещества (концентрация), добавленного к частицам, $K_{\text {sup }}$ - количество вещества в супернатанте после адсорбции. Загрузку частиц в wt.\% рассчитывали как отношение массы включенного вещества к массе частиц. Количество десорбированного фотодитазина определяли следующим образом: $\frac{K_{\text {free }}}{K_{\text {inc }}} \cdot 100 \%$, где $K_{\text {free }}-$ концентрация высвобожденного вещества в супернатанте, $K_{\text {inc }}$ - концентрация инкапсулированного вещества 

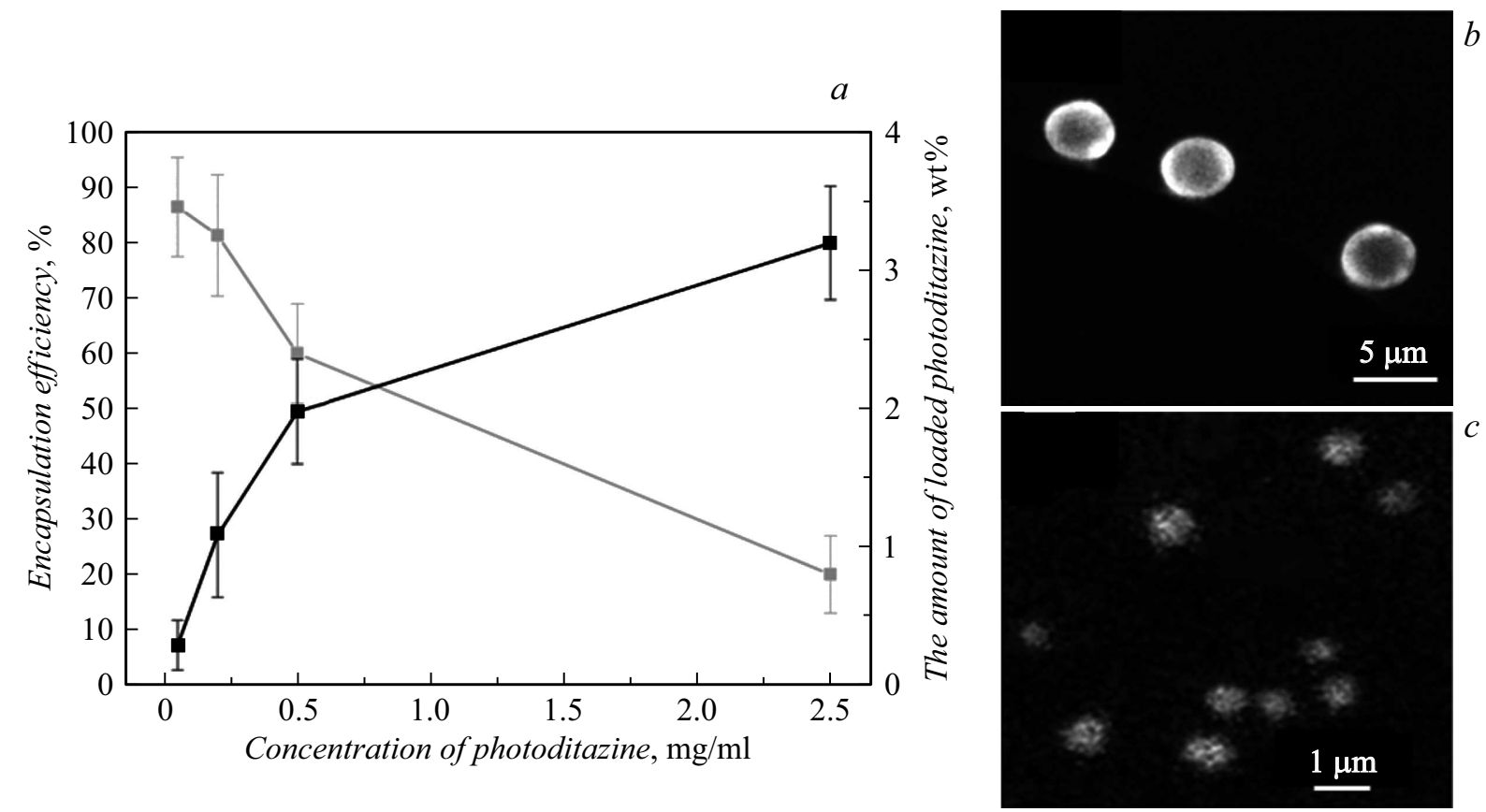

Рис. 1. Зависимость количества адсорбированного фотодитазина и эффективности капсулирования фотодитазина от концентрации раствора вещества при нагрузке $500 \mathrm{~nm}$ частиц ватерита $(a)$; конфокальные изображения частиц ватерита, нагруженных фотодитазином размером $5 \mu \mathrm{m}(b)$ и $500 \mathrm{~nm}(c)$.

в частицах. Данные, представленные на графиках, представляют собой усредненные значения по серии экспериментов (3-5 шт.), проведенных в одинаковых условиях и среднеквадратичные отклонения серии измерений.

\section{Измерение дзета-потенциала}

Измерение дзета-потенциала поверхности частиц в суспензии проводили с помощью автоматического анализатора Zetasizer Nano ZS (Malvern, Великобритания) при $25^{\circ} \mathrm{C}$.

\section{Лазерная сканирующая конфокальная микроскопия}

Визуализацию частиц ватерита с иммобилизованным фотодитазином проводили с помощью конфокального флуоресцентного микроскопа Leica TCS SP (Германия), снабженного иммерсионным объективом $\times 100$, имеющим цифровую апертуру 1.4. Флуоресценцию фотодитазина возбуждали лазером с длиной волны $633 \mathrm{~nm}$.

\section{Экспериментальные результаты и их обсуждение}

Оптимальные условия загрузки частиц ватерита фотодитазином были найдены в результате анализа зависимостей количества иммобилизованного вещества и эффективности капсулирования от концентрации раствора фотодитазина, взятого для адсорбции (рис. 1,a). Увеличивая концентрацию водного раствора фотодитазина до $2.5 \mathrm{mg} / \mathrm{ml}$, удалось достичь 3.2 и $3.0 \mathrm{wt} . \%$ загрузки контейнеров ватерита средним диаметром $500 \mathrm{~nm}$ и $5 \mu \mathrm{m}$ соответственно (использовали навески частиц одинаковой массы). Несмотря на то что средний размер частиц ватерита, использованных для экспериментов по адсорбции фотодитазина, различается на порядок, они имеют практически идентичные показатели пористости. Метод адсорбции/десорбции азота показал, что площадь поверхности составляет 16.1 и $15.5 \mathrm{~m}^{2} / \mathrm{g}$ для частиц диаметром 0.5 и $5 \mu \mathrm{m}$ соответственно [18]. Средний размер пор составляет 55 и $45 \mathrm{~nm}$ для частиц диаметром 0.5 и $5 \mu \mathrm{m}$ соответственно. Это объясняет то, что количество адсорбированного фотодитазина на частицах размером $5 \mu \mathrm{m}$ и $500 \mathrm{~nm}$ примерно одинаковое. При увеличении концентрации раствора выше $0.5 \mathrm{mg} / \mathrm{ml}$ количество иммобилизованного вещества растет медленнее наблюдается насыщение адсорбции фотодитазина на частицах ватерита. При этом снижается эффективность капсулирования: если для $0.5 \mathrm{mg} / \mathrm{ml}$ фотодитазина эта величина составляет $60 \%$, то для $2.5 \mathrm{mg} / \mathrm{ml}$ - только $20 \%$ (рис. 1,a).

На рис. $1, b$ представлены изображения в конфокальном микроскопе частиц с фотодитазином, демонстрирующие эффективную загрузку вещества в частицы ватерита двух размеров. На изображении частиц размером $5 \mu \mathrm{m}$ видно, что вблизи поверхности частиц флуоресценция фотодитазина имеет максимальную интенсивность. Это говорит о том, что большая часть вещества адсорбирована на поверхности частиц. 


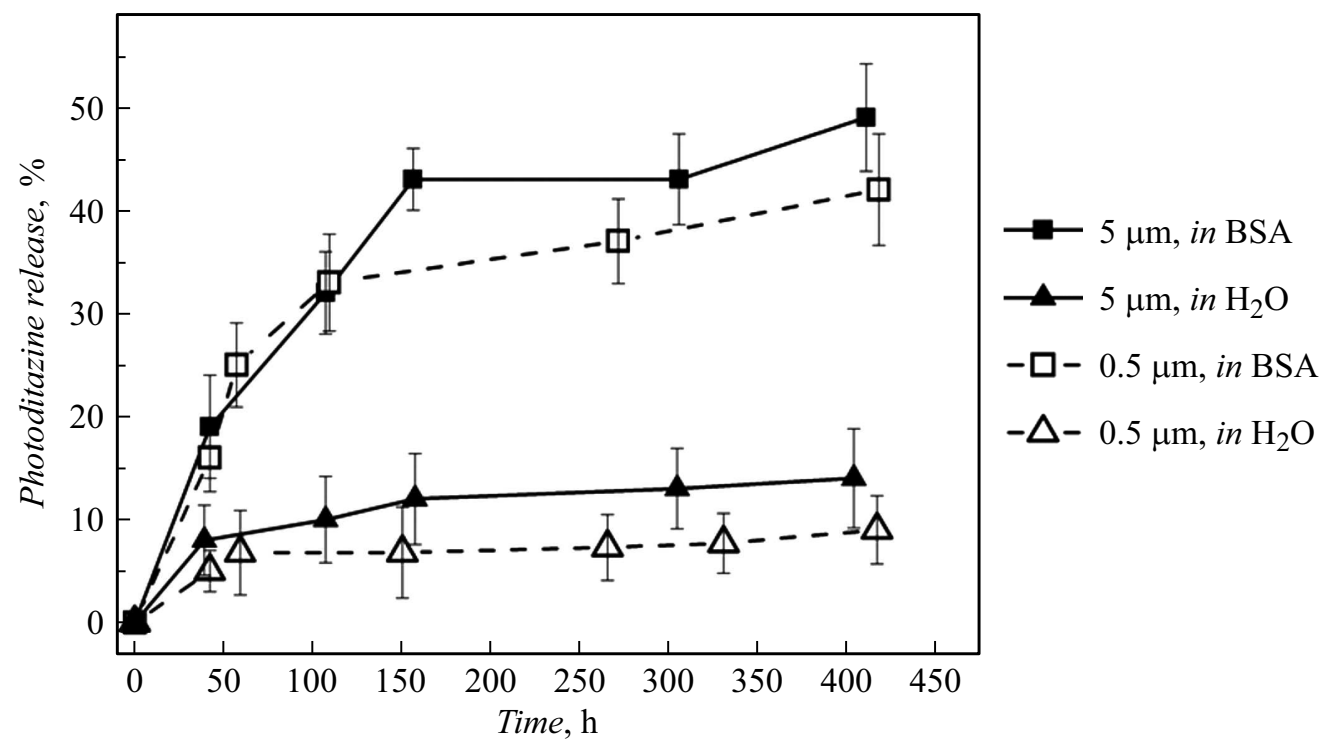

Рис. 2. Количество высвобожденного фотодитазина из частиц ватерита в зависимости от времени при различном составе среды.

Так как для экспериментов брали одинаковые навески частиц ватерита различного размера, то число использованных $0.5 \mu \mathrm{m}$ частиц существенно (в тысячу раз) больше, чем $5 \mu \mathrm{m}$ частиц. Так как оба образца имеют сравнимый wt.\% загрузки, то количество флуоресцентного вещества на одну субмикронную частицу получается меньше, чем на одну микронную частицу, что и объясняет более низкую интенсивность флуоресценции на рис. $1, c$.

В результате исследования высвобождения фотодитазина из контейнеров было показано, что интенсивность высвобождения существенно возрастает в присутствии белковых молекул (рис. 2). При инкубации в растворе бычьего сывороточного альбумина (БСА) в течение $114 \mathrm{~h}$ из частиц высвобождается около 30\% инкапсулированного вещества (для сравнения в воде высвобождается около 8-10\%). Это может быть обусловлено взаимодействием молекул фотодитазина с функциональными группами белка. Кроме того, из сравнения профилей кривых высвобождения вещества из 5 и $0.5 \mu \mathrm{m}$ частиц, можно сделать вывод, что размер частиц практически не влияет на интенсивность десорбции вещества (в пределах погрешности кинетические кривые почти совпадают).

В некоторых работах высвобождение вещества из частиц ватерита связывают с перекристаллизацией частиц, которая происходит при их инкубации в водной среде $[8,19]$. Однако при нахождении частиц в водном растворе фотодитазина частицы сохраняют свою структуру и практически не подвергаются перекристаллизации. Это было показано для частиц диаметром $5 \mu \mathrm{m}$ при инкубации в течение первых суток (рис. $3, a$ ) и частиц диаметром $500 \mathrm{~nm}$ при инкубации в течение четырех суток (рис. 3,b). Кроме того, несмотря на большое различие в площади поверхности одной частицы, скорость перекристаллизации крупных частиц выше, чем мелких (это отмечалось и ранее [19]). Это можно объяснить различием внутренней структуры частиц [18]. Причем с увеличением количества адсорбированного фотодитазина стабилизирующий эффект усиливается в отличие от „пустых “ частиц ватерита, перекристаллизация которых при хранении в воде происходит в течение нескольких часов.

О повышении устойчивости к перекристаллизации частиц ватерита в результате адсорбции фотодитазина говорит и изменение их электрокинетического потенциала. На рис. 4 представлены электрокинетические потенциалы интактных частиц ватерита, частиц ватерита с иммобилизованным фотодитазином и этих же частиц после инкубации в воде. У микронных частиц в результате адсорбции фотодитазина происходит перезарядка поверхности, что подтверждает успешную адсорбцию вещества на поверхность частиц (рис. 4,a). При дальнейшей инкубации этих частиц $\mathrm{c}$ фотодитазином в водной среде их дзета-потенциал не меняется в пределах погрешности (в том числе и при перекристаллизации). Дзета-потенциал субмикронных частиц после адсорбции сохраняет свой знак и величину (в пределах погрешности) поскольку частицы были изначально отрицательно заряжены. Интересно отметить, что с началом перекристаллизации частиц ватерита размером $0.5 \mu \mathrm{m}$ с фотодитазином в воде модуль дзета-потенциала уменышается (рис. $4, b)$. Это соответствует агрегации частиц ватерита перед их перекристаллизацией. На СЭМ изображении частиц после $264 \mathrm{~h}$ инкубации частиц в воде (рис. $3, b$ ) видно, что отдельные сферические частицы ватерита в значительной степени перекристаллизовались, и образец представляет собой в большей степени орторомбические кристаллы кальцита размером порядка нескольких микрометров. 


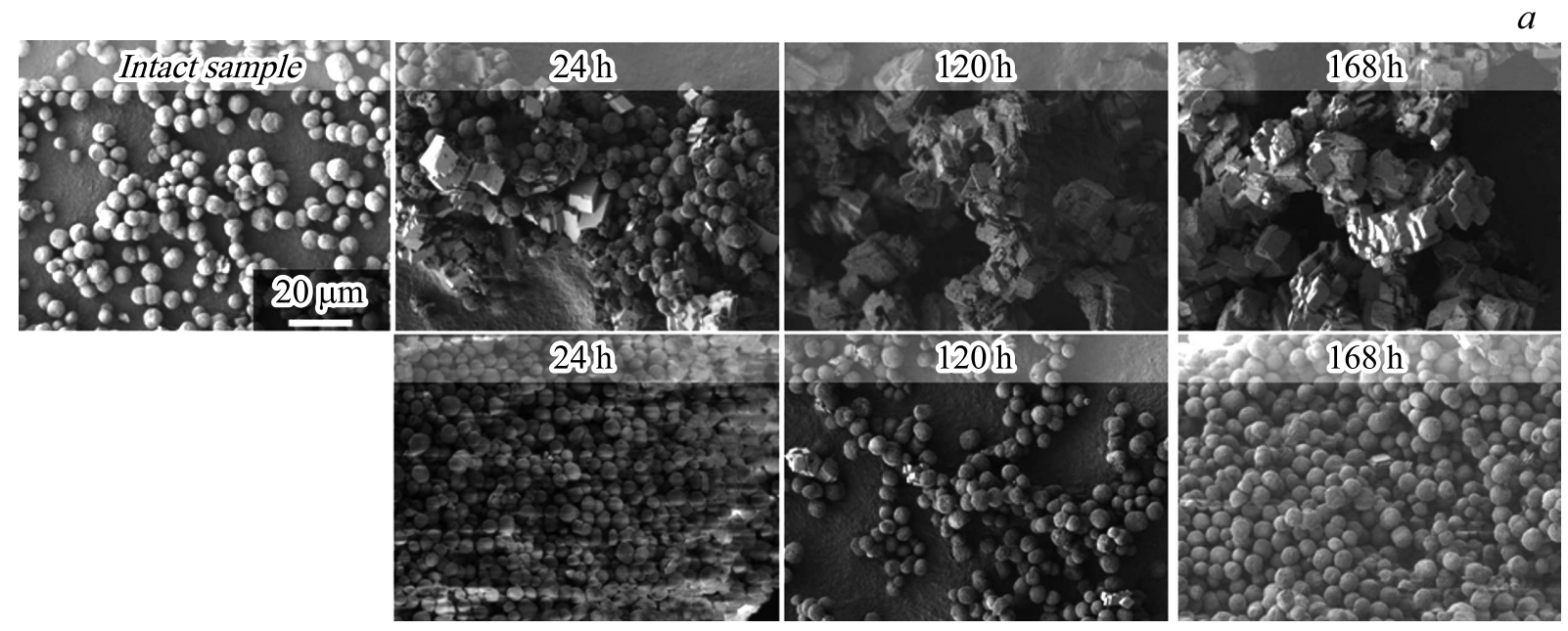

$b$
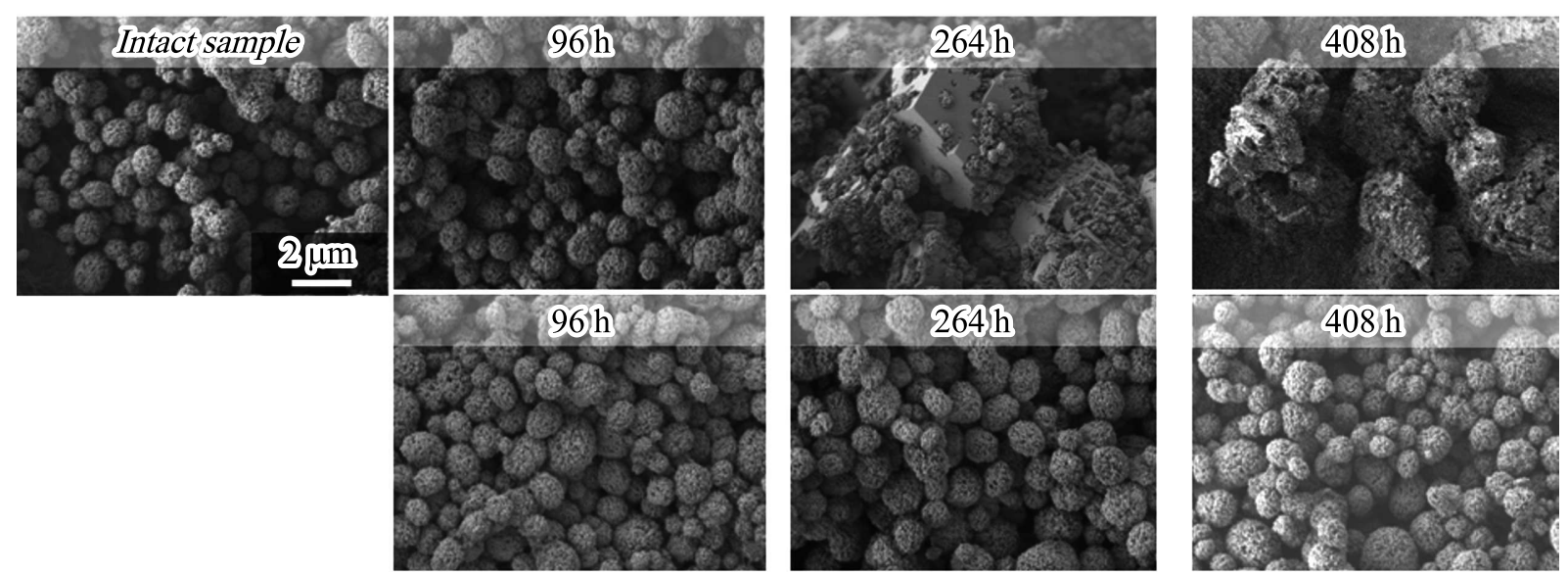

Рис. 3. СЭМ изображения частиц ватерита размером $5(a)$ и $0.5(b) \mu \mathrm{m}$ с фотодитазином после инкубации в деионизованной воде (первая строчка) или растворе белка (вторая строчка) в течение определенного времени. Шкала соответствует $20 \mu \mathrm{m}(a)$ и $2 \mu \mathrm{m}(b)$, изображения получены с одинаковым увеличением.

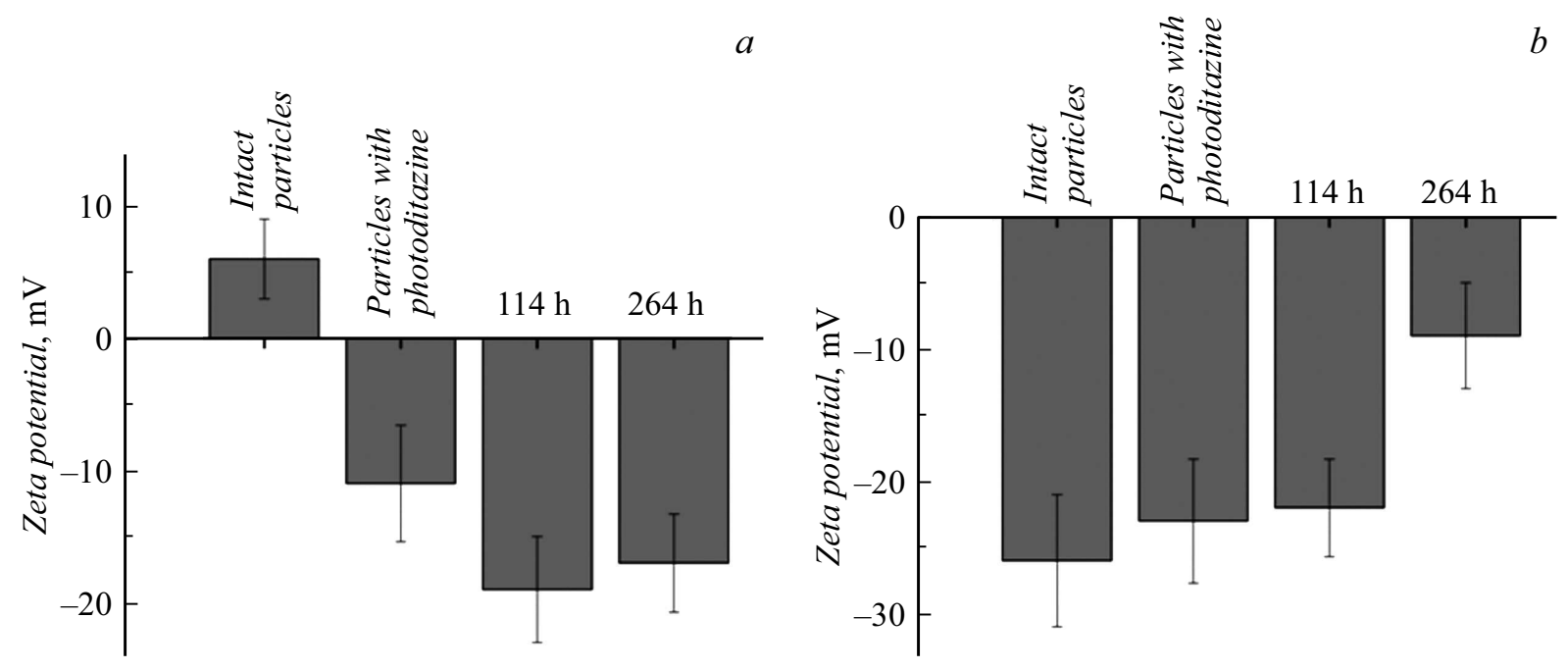

Рис. 4. Дзета-потенциалы частиц ватерита размером $5(a)$ и $0.5 \mu \mathrm{m}(b)$ после адсорбции фотодитазина и инкубации в воде. 
$a$
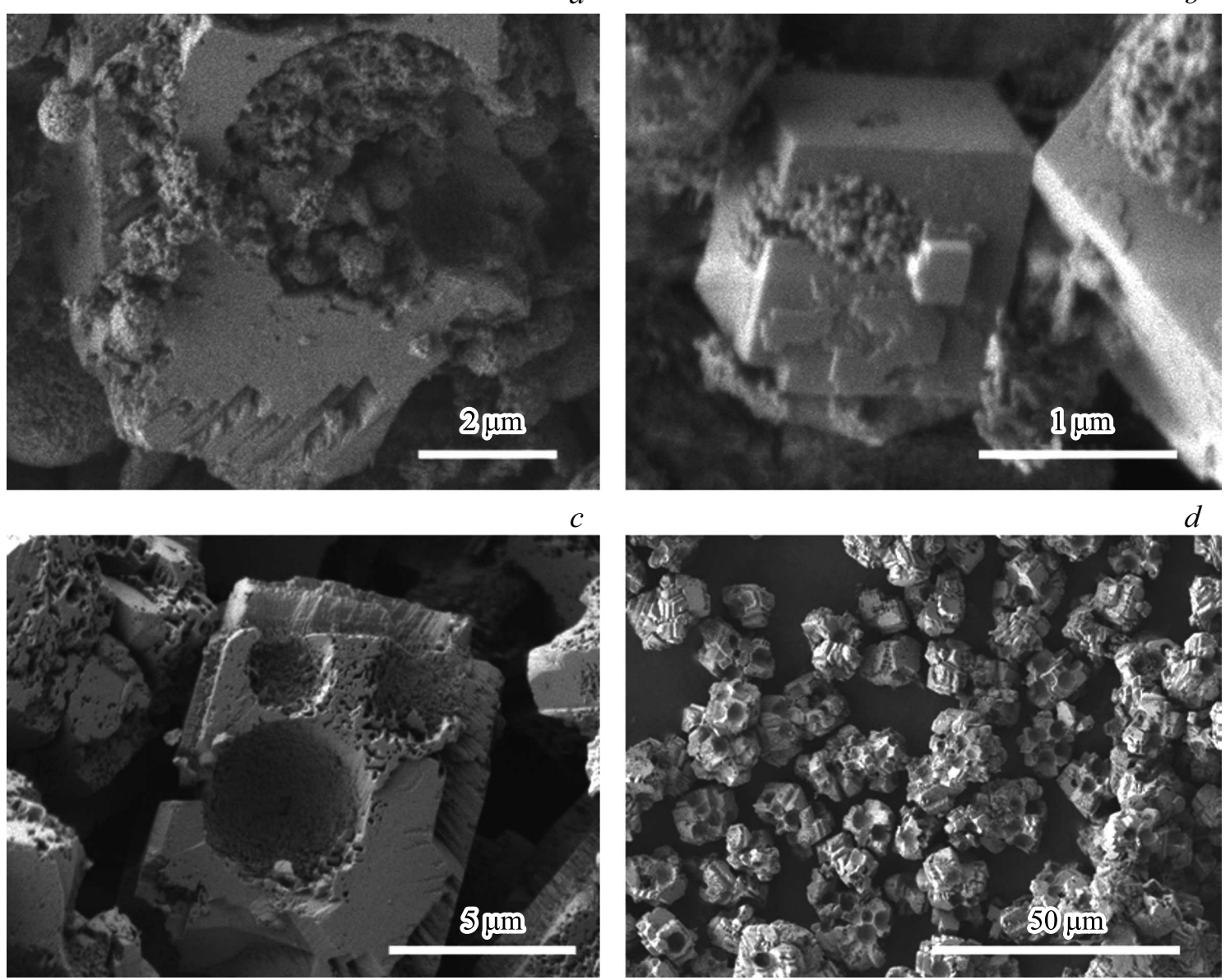

Рис. 5. СЭМ изображения частиц карбоната кальция, получившихся в результате перекристаллизации: частицы ватерита диаметром $0.5 \mu \mathrm{m} \mathrm{c}$ фотодитазином после инкубации в воде в течение $114 \mathrm{~h}(a, b)$, частицы ватерита диаметром $5 \mu \mathrm{m}$ с фотодитазином после инкубации в воде в течение $150 \mathrm{~h}(c, d)$.

Стабилизирующую роль для частиц ватерита с фотодитазином оказывает белок, присутствующий в дисперсионной среде. В экспериментах по высвобождению фотодитазина в раствор белка не удалось обнаружить заметных следов перекристаллизации частиц ватерита независимо от размера частиц (рис. 3). Частицы ватерита сохраняют свою сферическую форму, размер и структуру при инкубации в растворе белка, по крайней мере, в течение 7 и 17 суток (5 и $0.5 \mu \mathrm{m}$ частицы соответственно) (рис. 3). Это может быть обусловлено взаимодействием молекул фотосенсибилизатора с функциональными группами белка и образованием так называемой „белковой короны“ [20]. При этом смена воды не влияет на раствор белка и на дзета-потенциал частиц, который составляет $-25 \pm 4$ и $-22 \pm 5 \mathrm{mV}$ для суспензии в воде и растворе БСА соответственно.

В течение всего процесса инкубации частиц в той или иной дисперсионной среде с поверхности и из пор частиц происходит десорбция фотодитазина. Кривые высвобождения вещества из частиц имеют монотонный характер, который не меняется при перекристаллизации частиц (рис. 2, кривые, соответствующие десорбции фотодитазина в воду). Таким образом, БСА является эффективным ингибитором перекристаллизации карбоната кальция. Этот эффект присутствия молекул БСА в дисперсионной среде был также продемонстрирован для субмикронных ненагруженных частиц ватерита [3] они сохраняли свой полиморфный состав и размер в течение $96 \mathrm{~h}$.

Альбумин в высокой концентрации содержится в плазме крови, и концентрация раствора БСА, взятая для исследования кинетики высвобождения фотодитазина $(30 \mathrm{~g} / 1)$, практически соответствует физиологической концентрации. Таким образом, выбранная дисперсионная среда моделирует биологическое окружение при попадании частиц ватерита в организм.

Известно, что одним из возможных механизмов трансформации кристаллического осадка из менее стабильной фазы ватерита в более стабильную фазу кальцита является механизм „растворение--осаждение“ (растворениерекристаллизация) [21], когда частицы ватерита растворяются, а затем кристаллизуются частицы фазы с более низкой растворимостью в воде. На рис. 5 представлены типичные СЭМ изображения частиц, получившихся в 
результате инкубации частиц ватерита с фотодитазином в воде. Одновременное присутствие в образце фазы ватерита и кальцита продемонстрировано на рис. $5, a, b$. Зарождение и последующий рост кристаллов кальцита происходит вокруг сферической частицы, состоящей из множества зерен. На рис. 5, $а$ продемонстрирован промежуточный этап этого процесса, когда субмикронные частицы ватерита частично растворены и присутствуют только отдельные наночастицы. На рис. $5, b$ представлена практически заключительная стадия рекристаллизации, когда отдельных наноразмерных частиц ватерита становится меньше и образец представляет собой в большей степени ромбоэдрические кристаллы кальцита.

Другую особенность рекристаллизации можно отметить для микронных частиц ватерита. На рис. $5, c, d$ изображены частицы карбоната кальция с множеством сферических полостей характерного диаметра $3-5 \mu \mathrm{m}$, оставшихся от частиц ватерита. Предположительно поверхность интактных сферических частиц ватерита была подвержена частичному растворению, и высвобождающиеся карбонат-ионы и ионы кальция образовывали зародыши более стабильного полиморфа карбоната кальция (кальцита). Поскольку $\mathrm{CaCO}_{3}$ очень плохо растворимое в воде соединение, зародышеобразование и рост кристаллов кальцита идет очень быстро и локализуется непосредственно в месте, где появляются свободные ионы, т.е. у поверхности частицы. Таким образом, частицы ватерита, растворяясь, предоставляют ионы для кристаллизации кальцита и играют роль темплатов.

\section{Заключение}

Получены частицы ватерита со средним диаметром 5 и $0.5 \mu \mathrm{m}$, содержащие 3.0 и $3.2 \mathrm{wt} . \%$ фотодитазина соответственно. Показано, что высвобождение фотодитазина из частиц ватерита регулируется составом дисперсионной среды и слабо зависит от их размера. Молекулы фотодитазина ингибируют перекристаллизацию частиц ватерита как микронного, так и субмикронного размеров при их инкубации в воде, по крайней мере, в течение 24 и $96 \mathrm{~h}$ соответственно. При хранении частиц $(0.5 \mu \mathrm{m})$ с инкорпорированным фотодитазином в растворе БСА они сохраняют свою структуру и форму в течение более 17 суток.

Высокая эффективность иммобилизации фотосенсибилизатора на частицах ватерита размером $500 \mathrm{~nm}$, его постепенное высвобождение одновременно с продемонстрированной стабильностью частиц в модельной среде могут обеспечить высокую концентрацию препарата в опухоли и реализовать его пролонгированное высвобождение при введении в составе контейнеров на основе частиц ватерита.

Работа выполнена с использованием оборудования ресурсного центра НИЦ „Курчатовский институт“ и ЦКПФНИЦ „Кристаллография и фотоника“ РАН при поддержке Министерства образования и науки, а также при поддержке Федерального агентства научных организаций (соглашение № 007-ГЗ/Ч3363/26).

\section{Список литературы}

[1] Ярославцева-Исаева Е.В., Каплан М.А. // Российский биотерапевтический журнал. 2008. Т. 4. № 7. С. 36-41.

[2] Shirmanova M. etal. // J. Biomed. Opt. 2010. Vol. 15. N 4. P. 1-8.

[3] Lauth V., Maas M., Rezwan K. // Mater. Sci. Eng. C. 2017. Vol. 78. P. 305-314.

[4] Sukhorukov G.B. etal. // J. Mater. Chem. 2004. N 14. P. 2073-2081.

[5] Raliya $R$. etal. // RSC Adv. 2016. Vol. 6. N 59. P. 54331-54335.

[6] Ueno Y. etal. // J. Control. Release. 2005. Vol. 103. N 1. P. 93-98.

[7] Peng H. et al. // Nanoscale Res. Lett. 2013. Vol. 8. N 1. P. 321.

[8] Lakkakula J.R. etal. // RSC Adv. 2016. Vol. 6. N 106. P. 104537-104548.

[9] Wei W. etal. // J. Am. Chem. Soc. 2008. Vol. 130. N 47. P. 15808-15810.

[10] Ma M., Su R.-C. / Advances in Biomimetics. InTech. 2011. P. $13-50$.

[11] Won Y.-H. etal. // J. Mater. Chem. 2010. Vol. 20. N 36. P. 7728 .

[12] Donatan S. et al. // ACS Appl. Mater. Interface. 2016. Vol. 8. N 22. P. 14284-14292.

[13] Borodina T.N. et al. // Bionanoscience. 2016. Vol. 6. N 3. P. 261-268.

[14] Fujiwara M. et al. // Adv. Powder Technol. 2014. Vol. 25. N 3. P. $1147-1154$.

[15] Saikia J., Das G. // J. Environ. Chem. Eng. 2014. Vol. 2. N 2. P. 1165-1173.

[16] Sukhorukov G.B. et al. // J. Mater. Chem. 2004. Vol. 14. N 14. P. 2073-2081.

[17] Trushina D.B., Bukreeva T.V., Antipina M.N. // Cryst. Growth Des. 2016. Vol. 16. N 3. P. 1311-1319.

[18] Трушина Д.Б. идр. // Кристаллография. 2015. Т. 60. № 4. C. 625-633.

[19] Svenskaya Y. et al. // Biophys. Chem. 2013. Vol. 182. P. 11-15.

[20] Yan Y. et al. // ACS Nano. 2013. Vol. 7. N 12. P. 10960-10970.

[21] Davey R.J. etal. // J. Cryst. Growth. 1986. Vol. 79. N 1-3. P. 648-653. 